\title{
Left Anterolateral Segment
}

National Cancer Institute

\section{Source}

National Cancer Institute. Left Anterolateral Segment. NCI Thesaurus. Code C79733.

Couinaud segment III, corresponding to the lateral segment of the left lobe of the liver, located to the left of the inferior portion of the falciform lig ament, anteriorly overlapping the stomach. 